\title{
Structural Control Aiming for High-performance SiC Polycrystalline Fiber
}

\author{
Toshihiro Ishikawa** and Hiroshi Oda** \\ *Tokyo University of Science, Yamaguchi 756-0884, Japan \\ **Ube Industries, Ltd., Yamaguchi 755-8633, Japan \\ (Received September 2, 2016; Accepted September 12, 2016)
}

\begin{abstract}
SiC-polycrystalline fiber (Tyranno SA, Ube Industries, Ltd.) shows very high heat-resistance and excellent mechanical properties up to very high temperatures. However, further increase in the strength is required. Up to now, we have already clarified the relationship between the strength and the defect-size of the SiC-polycrystalline fiber. The defects are formed during the conversion process from the raw material (amorphous Si-Al-C-O fiber) into SiC-polycrystalline fiber. In this conversion process, a degradation of the Si-Al-C-O fiber and a subsequent sintering of the degraded fiber proceed as well, accompanied by a release of $\mathrm{CO}$ gas and compositional changes, to obtain the dense SiC-polycrystalline fiber. Since these changes proceed in each filament, the strict control should be needed to minimize residual defects on the surface and in the inside of each filament for achieving the higher strength. In this paper, the controlling factors of the fiber strength and the fine structure will appear.
\end{abstract}

Key words : SiC fiber, Tensile strength, Defect

\section{Introduction}

$\mathrm{T}$ he first continuous inorganic fiber was developed about 70 years ago. After that, lots of inorganic fibers have been developed. The adopted materials to develop these inorganic fibers are summarized in Table 1, whose information was published by W.C.Miller. ${ }^{1)}$ As can be seen from this table, of these materials, silicon carbide $(\mathrm{SiC})$ shows relatively balanced heat-resistances in both oxidizing and nonoxidizing atmospheres. So, up to now, lots of researches on $\mathrm{SiC}$ fibers have been performed, and then, the great progress in the specific characteristics of the developed $\mathrm{SiC}$ fibers has been achieved..$^{2-5)}$ By the way, the first SiC fiber was produced in the middle 1960 s by chemical vapor deposition onto tungsten or carbon filament core. However, as this type of $\mathrm{SiC}$ fiber had a large diameter (100 140 micron meters), the applications were limited. After that, the other type of SiC-based fiber with small diameters of about $10 \sim 20$ micron meters were synthesized from an organo-silicon polymer. This type of fiber was classified into a polymer-derived SiC fiber. The first polymer-derived SiC fiber was developed from polycarbosilane by Professor Yajima in the middle 1970s. ${ }^{6}$ After that, many types of polymerderived SiC-based fibers have been developed and commercialized. ${ }^{7,8)}$ These SiC-based fibers can show good mechanical strength and oxidation-resistance up to very high temperatures over $1000^{\circ} \mathrm{C}$. So, research and development on

${ }^{\dagger}$ Corresponding author : Toshihiro Ishikawa

E-mail : ishikawa@rs.tusy.ac.jp

Tel : +81-836-88-4564 Fax : +81-836-88-4564 composite materials using the SiC-based fibers have been widely performed. ${ }^{9-11)}$ Of these, stoichiometric SiC-polycrystalline fibers (Tyranno SA, and Hi-Nicalon Type S) show an excellent heat-resistance up to $2000^{\circ} \mathrm{C}^{3-5)}$ Accordingly, representative airplane engine manufacturers have actively evaluated these fibers. However, to extend the application field, increase in the mechanical strengths of these fibers is eagerly required. By the way, the production processes of the polymer-derived $\mathrm{SiC}$ fibers are very similar to that of carbon fiber. ${ }^{12)}$ Accordingly, regarding the improvements of the mechanical strength of these fibers, the history of the development of the strongest carbon fiber would be very

Table 1. Basic Information of Developed Inorganic Fibers

\begin{tabular}{|c|c|c|c|}
\hline \multirow{2}{*}{$\begin{array}{l}\text { Basic materials } \\
\text { for inorganic fibers }\end{array}$} & \multirow{2}{*}{$\begin{array}{l}\text { Melting } \\
\text { point }\left({ }^{\circ} \mathrm{C}\right)\end{array}$} & \multicolumn{2}{|c|}{ Heat resistance $\left({ }^{\circ} \mathrm{C}\right)$} \\
\hline & & In air & In inert gas \\
\hline B & 1260 & 560 & 1200 \\
\hline $\mathrm{SiO}_{2}$ & 1660 & 1060 & 1060 \\
\hline $\mathrm{Al}_{2} \mathrm{O}_{3}-\mathrm{SiO}_{2}-\mathrm{B}_{2} \mathrm{O}_{3}$ & 1740 & 1427 & 1427 \\
\hline $\mathrm{Al}_{2} \mathrm{O}_{3}-\mathrm{SiO}_{2}$ & 1760 & 1300 & 1300 \\
\hline $\mathrm{Al}_{2} \mathrm{O}_{3}-\mathrm{SiO}_{2}-\mathrm{Al}_{2} \mathrm{O}_{3}$ & 1760 & 1427 & 1427 \\
\hline $\mathrm{Si}_{3} \mathrm{~N}_{4}$ & 1900 & 1300 & 1800 \\
\hline $\mathrm{Al}_{2} \mathrm{O}_{3}$ & 2040 & 1540 & 1600 \\
\hline $\mathrm{ZrO}_{2}$ & 2650 & 1650 & 1650 \\
\hline $\mathrm{SiC}$ & 2690 & 1800 & 1800 \\
\hline $\mathrm{BN}$ & 2980 & 700 & 1650 \\
\hline $\mathrm{C}$ & 3650 & 400 & 2500 \\
\hline
\end{tabular}

W.C.Miller, Encyclopedia of Textiles, Fibers, and Nonwoven Fabrics (Edited by M Grayson Wiley, New York.) (1984) pp. $438-450$. 
suggestive for the study on the increase in the mechanical strength of the $\mathrm{SiC}$-based fibers. The tensile strength of first commercialized carbon fiber (T-300 produced by Toray Industries, Inc.) was only about $3 \mathrm{GPa}$. However, presently, the highest strength (about $7 \mathrm{GPa}$ ) has been successfully achieved by the same company. ${ }^{13,14)}$ Until the success, lots of defects contained in the inside and outside of each filament of the carbon fiber have been remarkably reduced. On the other hand, present tensile strengths of all commercial SiC fibers have been still around $3 \mathrm{GPa}$. The present stoichiometric SiC-polycrystalline fiber (Tyranno SA) also shows the almost similar strength. Tyranno SA is synthesized by further heat-treatment $\left(\sim 2000^{\circ} \mathrm{C}\right)$ of an amorphous Si-Al-CO fiber, which is synthesized from polyaluminocarbosilane. ${ }^{4)}$ During the aforementioned further heat-treatment, a degradation of the amorphous Si-Al-C-O fiber and a subsequent sintering of the degraded fiber proceed as well, accompanied by a release of $\mathrm{CO}$ gas and compositional changes, to obtain the dense SiC-polycrystalline fiber. Since these changes proceed in each filament, a strict control should be needed to minimize residual defects on the surface and in the inside of each filament. Considering the aforementioned present strength (around $3 \mathrm{GPa}$ ) of the stoichiometric SiC-polycrystalline fiber (Tyranno SA), this fiber must unfortunately contain some residual defects. So, the remarkable increase in the strength would be expected by an effective decrease in the residual defects. In this paper, the development story of the polymer-derived $\mathrm{SiC}$ fibers and the progress of the highest heat-resistant SiC-polycrystalline fiber will be addressed. And also, the important factors to decrease the residual defects will be discussed.

\section{Historical Points of SiC-based Fibers}

As mentioned before, SiC has a relatively balanced heatresistance both in air and in inert gas atmosphere. As the result of this, the research on the SiC-based fiber was started in the 1960s using CVD (chemical vapor deposition) onto a carbon filament or tungsten filament core. However, as this type of fiber had very large diameter $(100 \sim 140$ micron meters), the application was limited. After that, a polymer-derived SiC fiber with very small diameter $(10 \sim 20$ micron meters) was synthesized from polycarbosilane $\left(-\left(\mathrm{SiH}\left(\mathrm{CH}_{3}\right)-\mathrm{CH}_{2}-\right)_{\mathrm{n}}\right)$ by Professor Yajima. ${ }^{6)}$ Until the time, Professor Yajima had been strongly affected by the production process of carbon fiber which was synthesized by a thermal degradation of polyacrylonitrile (PAN) fiber. That is to say, making the best use of both the formability of the polycarbosilane to the fibrous shape and the conversion process from organic material to inorganic material, he achieved the great work. And also, regarding the synthesis of polycarbosilane, he was affected by a very important work achieved by Dr. Fritz. ${ }^{15)}$ Professor Yajima synthesized the first continuous polymer-derived SiC-based fiber by thermal-degradation of the precursor fiber made of polycarbosilane which was synthesized from polydimethylsilane $\left(-\left(\mathrm{Si}\left(\mathrm{CH}_{3}\right)_{2}\right)_{\mathrm{n}}\right)^{-}$.
On the basis of the aforementioned Yajima's process, Ube Industries Ltd. and Nippon Carbon Company had individually developed several types of commercial polymer-derived SiC-based fibers. And finally, SiC-polycrystalline fibers (HiNicalon Type S, Tyranno SA, and Sylramic) were developed. The historical points regarding the above-mentioned polymer-derived SiC-based fibers are summarized in Fig. 1. Of these polymer-derived SiC-based fibers, the SiC-polycrystalline fibers show the highest heat-resistance up to $2000^{\circ} \mathrm{C}$ and are classified into the third generation. Before the development of the third generation, several types of amorphous SiC-based fibers (Nicalon NL200, Tyranno Lox M, Tyranno S, Hi-Nicalon, and Tyranno ZMI) were developed and commercialized. Among these fibers, Hi-Nicalon and Tyranno ZMI are classified into the second generation whose heat-resistant temperature is around $1500^{\circ} \mathrm{C}$, whereas Nicalon NL200, Tyranno Lox M, and Tyranno S are classified into the first generation whose heat-resistant temperature is around $1300^{\circ} \mathrm{C}$. Through the long history, the fine structure of the polymer-derived SiC-based fibers had been changed from several types of amorphous structures to the stoichiometric SiC-polycrystalline structures along with a decrease in the oxygen content of each polymer-derived SiC fiber. And then, the aforementioned highest heat-resistant SiC-polycrystalline fibers (the third generation) were finally developed. Commercial polymerderived SiC-based fibers are shown in Table 2. As can be seen from this table, presently, commercial SiC-based fibers are produced and supplied by only three companies (NGS, UBE, and COIC) all over the world. In the next section, we would like to explain the improvement process from the first generation to the third generation using UBE's SiC-based fibers (Tyranno Lox M, Tyranno S, Tyranno ZMI, and Tyranno SA) shown in Table 2 as an example.

\subsection{Progress in UBE's SiC-based fibers}

Ube Industries, Ltd. has produced and commercialized several types of polymer-derived SiC-based fibers. The physical properties of these SiC-based fibers (Tyranno

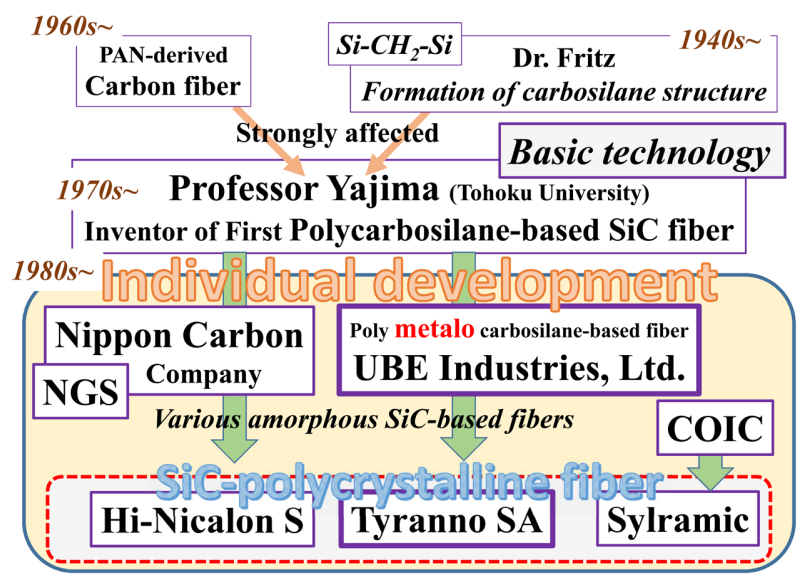

Fig. 1. Historical flow of the development of polymer-derived $\mathrm{SiC}$ fibers. 
Table 2. Commercial Polymer-Derived SiC Fibers

\begin{tabular}{cccc}
\hline & Fiber's Grade & Manufacturer & \\
\hline \multirow{2}{*}{ First Generation } & Nicalon NL 200 & NGS (Nippon Carbon) & Amorphous \\
$\sim 1300^{\circ} \mathrm{C}$ & Tyranno Lox M & UBE & Amorphous \\
& Tyranno S & UBE & \\
\hline Second Generation & Hi-Nicalon & NGS (Nippon Carbon) & SiC-Polycrystalline \\
$\sim 1500^{\circ} \mathrm{C}$ & Tyranno ZMI & UBE & \\
\hline \multirow{2}{*}{ Third Generation } & Hi-Nicalon Type S & NGS (Nippon Carbon) & UBE \\
$\sim 2000^{\circ} \mathrm{C}$ & Tyranno SA & COIC & \\
\hline
\end{tabular}

Table 3. Physical Properties of UBE's Polymer-Derived SiC Fibers

\begin{tabular}{lcccc}
\hline & $\mathrm{S}$ & $\begin{array}{c}\text { LoxM } \\
\left(\sim 1300^{\circ} \mathrm{C}\right.\end{array}$ & $\begin{array}{c}\text { ZMI } \\
\left(\sim 1500^{\circ} \mathrm{C}\right.\end{array} \begin{array}{c}\text { Tyranno SA } \\
\text { First generation })\end{array}$ & $\begin{array}{c}\left(\sim 2000^{\circ} \mathrm{C}\right. \\
\text { Second generation })\end{array}$ \\
Third generation $)$
\end{tabular}

fibers) are shown in Table 3. As can be seen from this Table, all of Tyranno fibers contain small amount of metal atoms ( $\mathrm{Ti}, \mathrm{Zr}$, or $\mathrm{Al}$ ). These metal atoms were introduced into each precursor polymer by a reaction of polycarbosilane with an organometallic compound. By the use of these precursor polymers, the aforementioned SiC-based fibers containing metal atoms were obtained. And also, as can be seen from Table 3 , the content of oxygen was remarkably reduced from the first generation to the third generation. The reduction in the oxygen content results in the increase in the heat-resistance from $1300^{\circ} \mathrm{C}$ to $2000^{\circ} \mathrm{C}$. By the way, the carbon contents of these SiC-based fibers are different from each other. The atomic ratios $(\mathrm{C} / \mathrm{Si})$ of carbon and silicon of LoxM (first generation), ZMI (second generation), and Tyranno SA (third generation) are 1.36, 1.42, and 1.08, respectively. That is to say, both the first generation and the second generation contain relatively large amount of excess carbon compared with the third generation which shows a nearly stoichiometric $\mathrm{SiC}$ composition. The aforementioned excess carbon was caused from the polycarbosilane (-( $\left.\left.\mathrm{SiH}\left(\mathrm{CH}_{3}\right)-\mathrm{CH}_{2}-\right)_{\mathrm{n}}\right)$ which contains the higher content of carbon compared with that of silicon.
The fine structure of the first generation and the second generation is shown in Fig. 2. Both the first and second generations are composed of $\mathrm{SiC}$ fine crystal, oxide phase, and excess carbon. As long as the excess carbon and the oxide phase exist, a degradation reaction $\left(\mathrm{SiO}_{2}+3 \mathrm{C} \rightarrow \mathrm{SiC}+2 \mathrm{CO}\right)$ easily occurs over $1522^{\circ} \mathrm{C}$ accompanied by a release of $\mathrm{CO}$ gas and a formation of $\mathrm{SiC}$ crystal. By this degradation reaction, both the first generation and the second generation show a remarkable decrease in the tensile strengths over $1500^{\circ} \mathrm{C}$. However, making the best use of the aforementioned degradation reaction, the nearly stoichiometric $\mathrm{SiC}$ composition of the third generation was achieved as shown in Fig. 3 which shows the production process of the third generation (Tyranno SA). The precursor polymer of the third generation (Tyranno SA) is polyaluminocarbosilane containing small amount of aluminum. After curing in air of the precursor fiber, the cured precursor fiber was fired in nitrogen atmosphere at about $1300^{\circ} \mathrm{C}$, and then an amorphous Si-Al-C-O fiber was obtained. After that, this amorphous Si-Al-C-O fiber was heat-treated at higher temperatures $\left(\sim 2000^{\circ} \mathrm{C}\right)$ in $\mathrm{Ar}$ atmosphere. During the heat- 


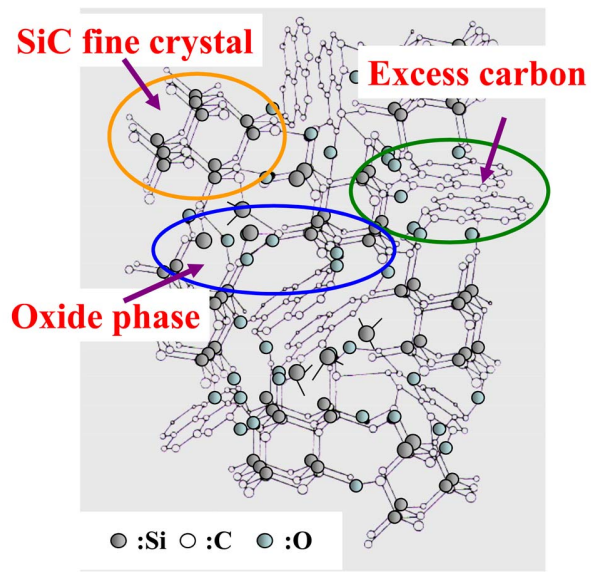

Fig. 2. The fine structure of the first generation and the second generation.

treatment at higher temperatures, by the existence of the oxide phase and excess carbon in the fiber, the amorphous $\mathrm{Si}$ $\mathrm{Al}-\mathrm{C}-\mathrm{O}$ fiber was degraded accompanied by the release of $\mathrm{CO}$ gas to obtain a porous degraded fiber. This degradation of the Si-Al-C-O fiber proceeds mainly by the following reactions.

$$
\begin{aligned}
& \mathrm{SiO}_{2}+3 \mathrm{C}=\mathrm{SiC}+2 \mathrm{CO}\left(\Delta \mathrm{G}<0 \text { over } 1522^{\circ} \mathrm{C}\right) \\
& \mathrm{SiO}+2 \mathrm{C}=\mathrm{SiC}+\mathrm{CO} \\
& (\Delta \mathrm{G}<0 \text { at all temperatures range })
\end{aligned}
$$

The porous degraded fiber was composed of a nearly stoichiometric SiC composition containing small amount of aluminum (less than $1 \mathrm{wt} \%$ ). By the existence of the small amount of aluminum, at the next step, an effective sintering proceeded in each degraded filament composed of the nearly stoichiometric $\mathrm{SiC}$ crystals during further heat-treatment up to $2000^{\circ} \mathrm{C}$ in $\mathrm{Ar}$ gas atmosphere. And then, the dense SiC-polycrystalline fiber (Tyranno SA) was obtained. The morphological changes of each filament during the further heat-treatment are shown in Fig. 4. As can be seen from this figure, during the further heat-treatment, the degradation of each filament smoothly proceeded from surface to inside, and after that at higher temperatures over $1700^{\circ} \mathrm{C}$ the dense structure was effectively created by sintering phenomenon (solid phase sintering) caused by the existence of small amount of aluminum $(<1 \mathrm{wt} \%)$ contained in each $\mathrm{SiC}$ crystal as a solid solution. The important thing is that all of these changes quantitatively proceed as an in-situ process.

\section{The Fine Structure of Tyranno SA}

As mentioned before, the production process of the SiCpolycrystalline fiber is very similar to that of carbon fiber, which is composed of melt-spinning, curing, firing, and further heat-treatment (decomposition and densification) at higher temperatures in inert gas atmosphere. The early carbon fiber showed the almost similar tensile strength $(\sim 3$ $\mathrm{GPa}$ ) to that of present SiC-polycrystalline fiber. However, presently, the highest strength (about $7 \mathrm{GPa}$ ) of carbon fiber has been successfully achieved by reducing lots of defects contained in each filament. That is to say, the early carbon fiber contained many defects in the inside and the outside of each filament. So, it was considered that present Tyranno SA must contain lots of defects as shown in Fig. 5. Actually, some defects in the sliced specimen of the SiC-polycrystalline fiber were detected (Fig. 5).

In general, modulus, thermal conductivity, melting point, special heat, thermal expansion, density, and so on, are classified into an intrinsic property. On the other hand, strength and proportional limit are classified into nonintrinsic property dominated by "Defects". Accordingly, to increase the strength of the SiC-polycrystalline fiber, effective decrease in the defects contained in each filament has to be achieved. Aiming to this achievement, firstly we investigated the relationship between the defects and the

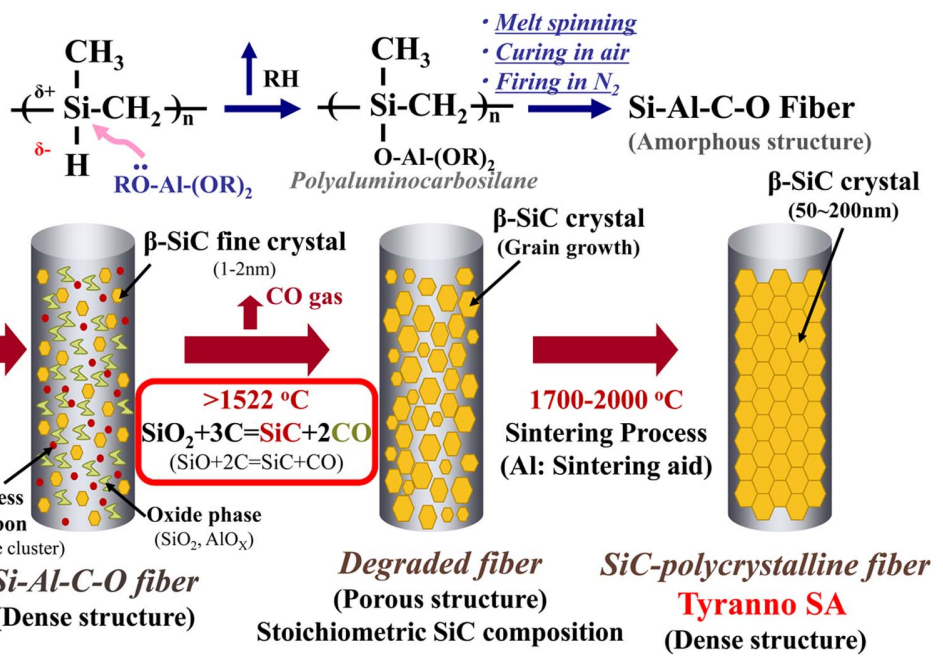

Fig. 3. Production process of the SiC-polycrystalline fiber. 


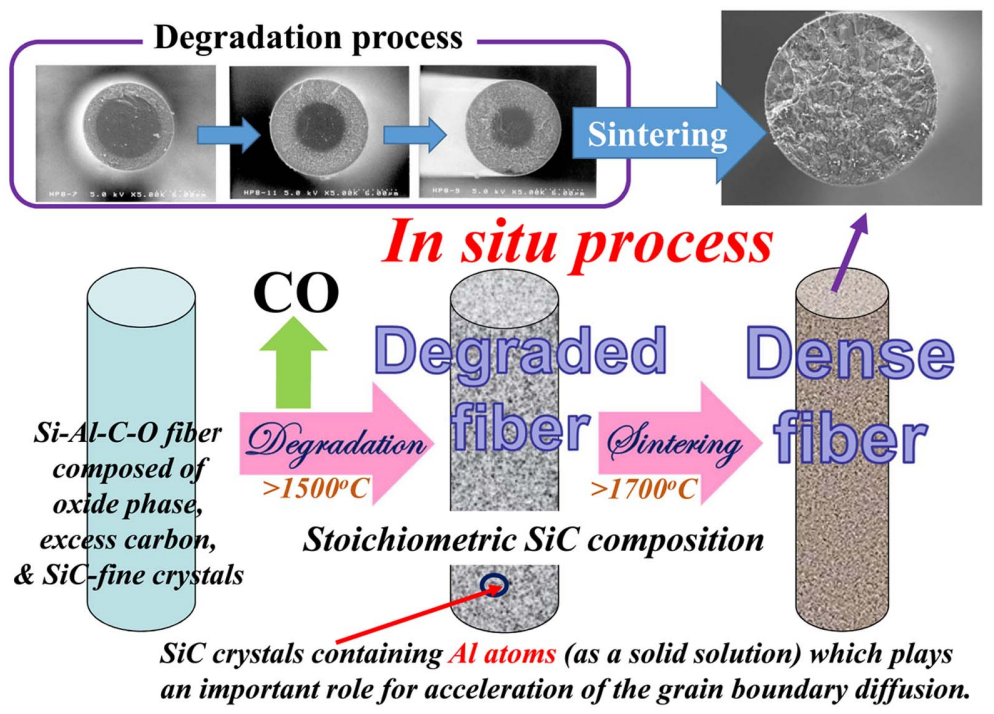

Fig. 4. Morphological changes during the further heat-treatment.

strength in detail. Most of defects were (1) pore, (2) dislocated carbon, and (3) an abnormal crystalline growth (very few case). We had already developed some technics for the actual detection of defects. Using this technology, we obtained the relationship between the flaw size and the tensile strength whose results were published in other paper. ${ }^{2)}$ The smaller the defect size was, the higher the strength became. Accordingly, in order to increase the strength, we have to decrease the flaw size less than $100 \mathrm{~nm}$. To achieve this objective, strict control of the degradation reaction and sintering process indicated in Fig. 4 is needed. During these processes, lots of changes proceed in a competitive way. The possible changes during the further heat-treatment are summarized in Fig. 6. Of these, the strict control of the following reactions is most important to obtain the dense structure.

$$
\begin{aligned}
& \mathrm{SiO}_{2}+3 \mathrm{C}=\mathrm{SiC}+2 \mathrm{CO} \quad \text { Main reaction } \\
& \left(\Delta \mathrm{G}<0 \text { over } 1522^{\circ} \mathrm{C}\right) \\
& \mathrm{SiO}+2 \mathrm{C}=\mathrm{SiC}+\mathrm{CO} \quad \text { Main reaction } \\
& (\Delta \mathrm{G}<0 \text { at all temperatures range })
\end{aligned}
$$

Specifically, preventing the disappearance of $\mathrm{SiO}$ gas from each filament and controlling the partial pressure of released $\mathrm{CO}$ gas are very important for obtaining the higher strength. If the gaseous $\mathrm{SiO}$ disappears from the fiber, consequently the residual carbon would be undesirably remained in the degraded fiber, and then it would become difficult to obtain the stoichiometric composition. Accordingly, we have to strictly control the Ar gas flow and atmospheric conditions in the reactor. And also, this is important for preventing the abnormal growth of $\mathrm{SiC}$ crystals on the surface region of each filament. This phenomenon is closely related to the surface roughness of the obtained SiC-polycrystalline fiber. Furthermore, in this degradation reaction,

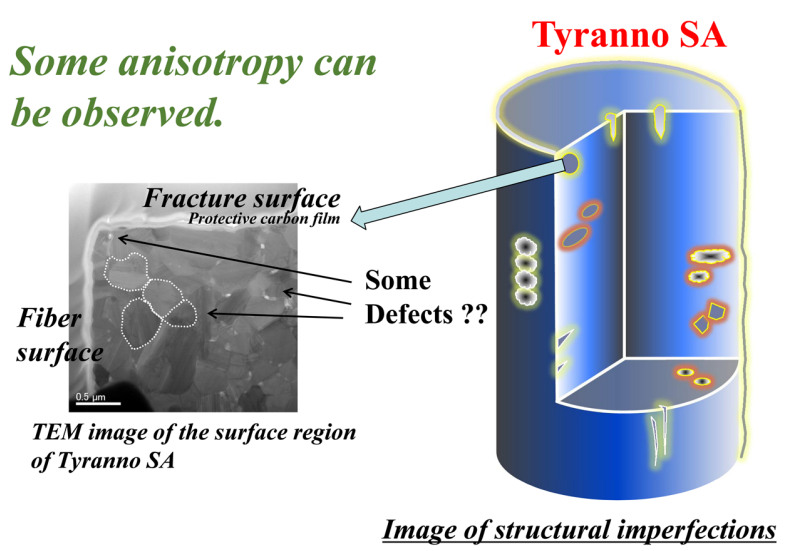

Fig. 5. Estimated defects contained in SiC-polycrystalline fiber.

we have to consider the "Le Chatelier's principle". That is to say, the degradation rate is dominated by the partial pressure of CO gas. As can be seen from the aforementioned reaction equations, this degradation proceeds accompanied by the release of $\mathrm{CO}$ gas. Accordingly, when reduced the concentration of $\mathrm{CO}$ gas in the reactor, the degradation proceeded much more rapidly. On the other hand, when increased the concentration of $\mathrm{CO}$ gas in the reactor, the degradation was suppressed. And also, these conditions were closely related to the $\mathrm{SiC}$ crystalline size of the obtained SiC-polycrystalline fiber.

By strictly controlling these factors, it could be confirmed that the surface roughness and the $\mathrm{SiC}$ grain size were effectively controlled. The crystalline size of the formed SiC crystal depends on two kinetic steps, that is to say, nucleation and grain growth. In this case, the former nucleation depends on the degradation rate, which is dominated by the concentration of $\mathrm{CO}$ gas and heating rate. According to "Le Chatelier's principle", reducing the concentration of CO gas, where the degradation rate becomes fast, can accelerate the 


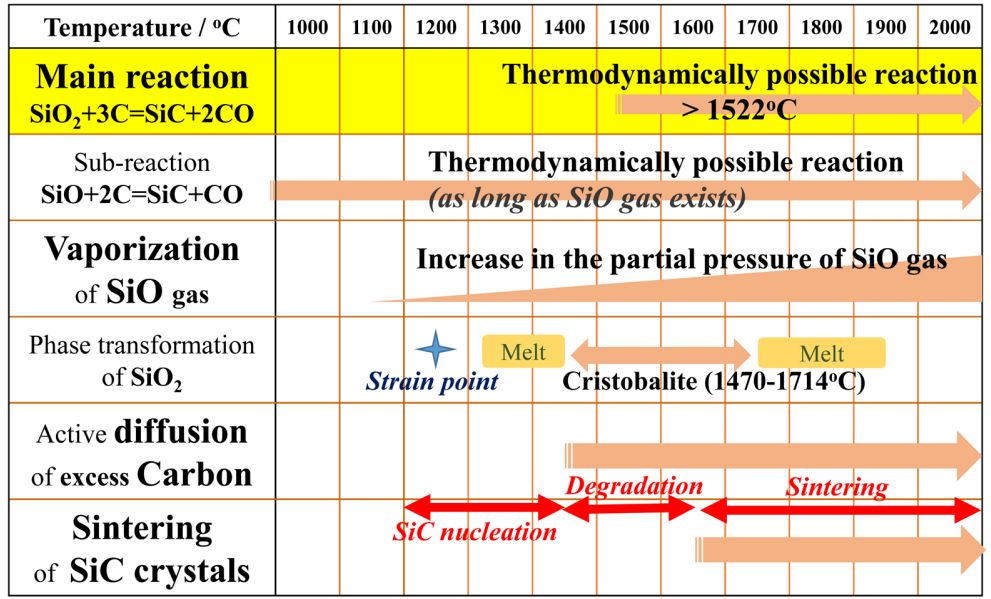

Fig. 6. Possible changes during the further heat-treatment.

nucleation, and then consequently can reduce the size of the formed SiC crystals. Finally, the improvement of the surface roughness was achieved by reducing the total pressure in the reactor (around $10 \mathrm{MPa}$ ). And also, the crystalline size was remarkably reduced from $69 \mathrm{~nm}$ to $50 \mathrm{~nm}$.

\section{Conclusions}

Since the first glass fiber developed in 1940s, lots of inorganic fibers have been developed. Of these inorganic fibers, SiC-based fiber showed the most balanced high temperature strength both in air and in inert atmosphere. Through the long research on higher heat-resistant inorganic fibers, a polymer-derived SiC-based fiber with small diameter had been developed. After that, several grade of polymer-derived SiC-based fibers have been developed, and finally the highest heat-resistant SiC-polycrystalline fibers (Hi-Nicalon Type S, Tyranno SA, Sylramic) were developed. Of these, Tyranno SA was produced via lots of heat-treatment procedure using a precursor polymer. This production process is very similar to that of carbon fiber. The production process of carbon fiber is composed of melt-spinning, curing, firing, and further heat-treatment (decomposition \& densification) at higher temperatures in inert gas atmosphere. Since both production processes contain lots of heat-treatment procedure accompanied by the gaseous by-products, it's easy to remain macro- or micro-pores in each filament. These pores would become "defect" as well as both residual carbon and other anisotropy, and also an abnormal crystalline growth becomes remarkable defects. The highest strength of carbon fiber ( 7 GPa) was successfully achieved by remarkably reducing lots of defects. Up to now, it has been confirmed that the smaller the defect size became, the higher the strength became. Aiming to decreasing the defect size, by controlling the degradation and sintering processes, both remarkably smooth surface and smaller crystalline size of the SiC-polycrystalline fiber were experimentally obtained.

\section{Acknowledgments}

This study was funded by Grant-in Aid for Scientific Research from Japan Society for the Promotion of Science (Grant-in-Aid for Research Activity Start-up, 2016). We gratefully acknowledge this financial support.

\section{REFERENCES}

1. W.C.Miller, Encyclopedia of Textiles, Fibers, and Nonwoven Fabrics; pp. 438-50, Edited by M.Grayson Wiley, New York, 1984.

2. T. Ishikawa and H. Oda, "Defect control of SiC Polycrystalline Fiber Synthesized from Poly-Aluminocarbosilane," J. Eur. Ceram. Soc., 36 [11] 3657-62 (2016).

3. T. Ishikawa, "Heat-resistant Inorganic Fibers," Adv. Sci. Technol., 89 129-38 (2014).

4. T. Ishikawa, Y. Kohtoku, K. Kumagawa, T. Yamamura, and T. Nagasawa, "High-Strength Alkali-Resistant Sintered SiC Fibre Stable to $2200^{\circ} \mathrm{C}$," Nature, 391 773-75 (1998).

5. M. Takeda, A. Urano, J. Sakamoto, and Y. Imai, "Microstructure and Oxidative Degradation Behavior of Silicon Carbide Fiber Hi-Nicalon Type S," J. Nucl. Mater., 258 1594-99 (1998).

6. S. Yajima, M. Omori, J. Hayashi, K. Okamura, T. Matsuzawa, and C. Liaw, "Symple Synthesis of the Continuous SiC Fiber with High Tensile Strength," Chem.Lett., 1976 [6] 551-54 (1976).

7. O. Flores, R. K.Bordia, D. Nestler, W. Krenkel, and G. Motz, "Ceramic Fibers Based on $\mathrm{SiC}$ and SiCN Systems: Current Research, Development, and Commercial Status," Adv. Eng. Mater., 16 [6] 621-36 (2014).

8. P. Colombo, G. Mera, R. Riedel, and G. D. Soraru, "Polymer-Derived Ceramics: 40 Years of Research and Innovation in Advanced Ceramics," Ceram. Sci. Technol., Set, 2013 245-320 (2013).

9. J. J.Sha, T. Nozawa, J. S.Park, Y. Katoh, and A. Kohyama, "Effect of Heat Treatment on the Tensile Strength and Creep Resistance of Advanced SiC Fibers," J. Nucl. Mater., 329 592-96 (2004). 
10. K. Itatani, K. Hattori, D. Harima, M. Aizawa, and I. Okada, "Mechanical and Thermal Properties of SiliconCarbide Composites Fabricated with Short Tyranno Si-ZrC-O Fiber,” J. Mater. Sci., 36 3679-86 (2001).

11. N. Remirez de Esparza, N. Cocera, L. Vazquez, J. Alkorta, I. Ocana, and J. M. Sanchez, "Characterization of CVD Bonded Tyranno Fibers Oxidized at High Temperaturs," $J$. Am. Ceram. Soc., 97 [12] 3958-66 (2014).

12. N. Yusof, and A. F. Ismail, "Post Spinning and Pyrolysis Processes of Polyacrylonitrile (PAN)-Based Carbon Fiber and Activated Carbon Fiber: A Review," J. Anal. Appl. Pyrolysis, 93 1-13 (2012).

13. J. Liu, Z. Yue, and H. Fong, "Continuous Nanoscale Carbon Fibers with Superior Mechanical Strength,” Small, 5 [5] 536-42 (2009).

14. F. Tanaka, T. Okada, H. Okuda, I. A. Kinloch, and R. J. Young, "Factors Controlling the Strength of Carbon Fibers in Tension," Composites, Part A, 57 88-94 (2014).

15. G.Fritz, "Bildung Siliciumorganischer Verbindungen . III. Mitt.: Zum thermischen Zerfall von $\mathrm{SiH}_{4}$," Zeitschrift für Naturforschung, 7 [9-10] 507-8 (1952). 